\title{
MEMANFAATKAN POTENSI LOKAL KEFAMENANU DALAM PEMBELAJARAN MATEMATIKA UNTUK MENINGKATKAN KREATIVITAS GURU SMP
}

\author{
Stanislaus Amsikan"), Yohanis Ndapa Deda') \\ Fakultas Pendidikan Matematika, Program Studi Pendidikan Matematika \\ Universitas Timor, Indonesia1),2) \\ Pos-el: yndapadeda@ymail.com ${ }^{2)}$
}

Diterbitkan: 29 Agustus 2018

\begin{abstract}
Abstrak
Tujuan dari pengabdian ini adalah untuk meningkatkan kreativitas guru dalam membuat Lembar kerja Siswa (LKS) dengan memanfaatkan Potensi lokal yang ada di Kefamenanu, Kabupaten Timor Tengah Utara (TTU). Potensi lokal yang kami maksud dalam penelitian ini adalah makanan khas lokal yaitu Laku Tobe, Jambu Biji lokal daerah Timor, rumah adat Ume Kbubu, dan kain tenun adat motif sotis. Metode yang digunakan adalah metode ceramah, workshop, dan Praktek. Metode Ceramah digunakan untuk menyampaikan gambaran umum dan contoh pemananfatan potensi lokal dalam pembelajaran matematika,kemudian dilanjutkan dengan workshop analisis materi kompetensi dasar dan kompetensi inti yang sesuai dengan potensi lokal, tahap terakhir adalah praktek, dimana guru sebagai peserta workshop mengajar di kelas menggunakan LKS berbasis potensi lokal. Hasil penelitian menunjukkan bahwa Potensi lokal Laku Tobe, Jambu Biji, Ume Kbubu, dan kain tenun yang ada di Kefamenanu telah terbukti meningkatkan kreativitas guru dalam membuat perangkat pembelajaran berupa LKS untuk menjembatani siswa memahami konsep matematika seperti bangun datar, bangun ruang, dan pola bilangan.
\end{abstract}

Kata kunci: potensi, local, pembelajaran, matematika, konsep

\section{Abstract}

The purpose of this study is to creative teachers in making worksheets students (LKS) using local potential in Kefamenanu, North Central Timor Regency (TTU). Local potential that we meanin this research is local traditional food laku tobe, guava local in timor region, traditional house ume kbubu, and sotis woven traditional motives. The methods used is discourse, workshop, and practice. This method used to convey an overall picture and example using local potential in learning math, then followed by analysis of main competence and basic competence in wich coresponding to the potential local, the final phase is practice, where teachers as participants workshop follow in the classroom using LKS based potential local. The result shows that laku tobe 
local potential, guava, ume kbubu, and motif woven in kefamenanu has been proven creative teachers.

Key words: local, potential, learnin, mathematics, concept

\section{PENDAHULUAN}

Pada saat pembelajaran matematika di kelas, umumnya guru belum menggunakan atau mengoptimalkan lingkungan sekitar siswa atau budaya lokal yang dekat dengan kehidupan siswa. Guru belum menggunakan konteks yang dekat dengan kehidupan siswa, belum menggunakan lingkungan sekitar siswa sebagai potensi lokal yang dapat digunakan untuk memudahkan pembelajaran matematika. Peranan potensi lokal dalam pembelajaran matematika adalah sebagai jembatan dari sesuatu yang tidak formal atau konkrit ke sesuatu yang formal atau abstrak. Potensi lokal akan membawa pembelajaran matematika lebih bermakna karena dikerjakan lewat aktivitas-aktivitas siswa dalam menemukan kembali konsep matematika. ide ini telah diperkuat oleh Hans Freudenthal pada tahun 1971 yang menyatakan bahwa "mathematics is a human activity". Beberapa hasil penelitian terkait penggunaan potensi lokal, adanya hubungan motif kain tenun masyarakat Suku Dawan di Kabupaten TTU dengan matematika sekolah (Deda \& Disnawati, 2017), adanya hubungan ume kbubu dengan pembelajaran konsep geometri dasar yang dipelajari di sekolah dasar dan sekolah menengah, seperti pengenalan bentuk bangun datar dan bangun ruang, yaitu lingkaran, kerucut, dan selinder atau tabung (Amsikan \& Nahak, 2017). Hasil penelitian tersebut di atas hanya sebatas mengeksplorasi kaitan antara potensi local yang ada di masyarakat kefamenanu dengan matematika sekolah, belum sampe pada implementasi ke dalam proses pembelajaran matematika. untuk itu, pelaksanaan pengabdian yang memanfaatkan potensi local dalam pembelajaran matematika perlu dilaksanakan.

Tujuan yang ingin dicapai dari pengabdian masyarakat ini adalah memanfaatkan potensi lokal dalam pembelajaran matematika untuk meningkatkan kreativitas guru. Potensi lokal yang ada di Kefamenanu sangat banyak dan mengingat keterbatasan waktu dan tenaga, maka perlu dibatasi potensi lokal yang dimaksud. Potensi lokal yang kami maksud dalam makalah ini adalah makanan khas lokal yaitu Laku Tobe, Jambu Biji lokal daerah Timor, rumah adat Ume Kbubu, permainan tradisional Siki Doka, dan kain tenun adat motif Buna. Laku Tobe; laku bermakna 'ubi', tobe bermakna 'anyaman', alat pembuatan makanan laku tobe berbentuk kerucut. Laku Tobe adalah salah satu makanan khas orang Timor yang dibuat dengan bahan dasar ubi kayu. Makanan ini biasa disajikan berbentuk kerucut mirip nasi tumpeng. Disajikan pada acara adat, pada saat penen, memungut hasil panen, dan bisa juga sebagai Ole-ole. 


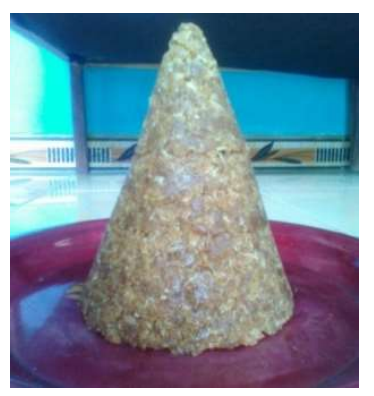

Gambar 1: Laku Tobe, Mei 2017

Jambu Biji lokal daerah Timor

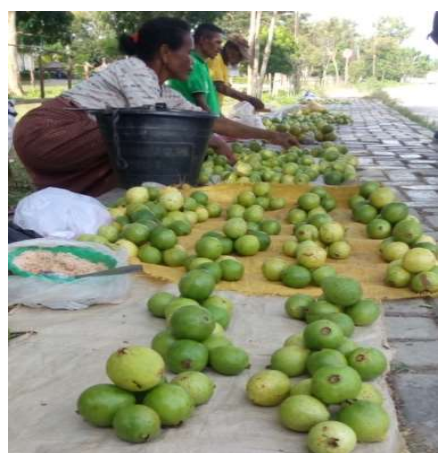

Gambar 2: Jambu Biji, April 2017

Menurut Banamtuan (2015) Rumah Bulat atau Ume Kbu'bu' yaitu rumah yang atapnya mendekati permukaan tanah dengan pintu yang rendah. Atap Ume Kbu'bu' yang mendekati atau sampai dengan tanah terbuat dari alang-alang atau daun gewang yang diikat dengan tali hutan.

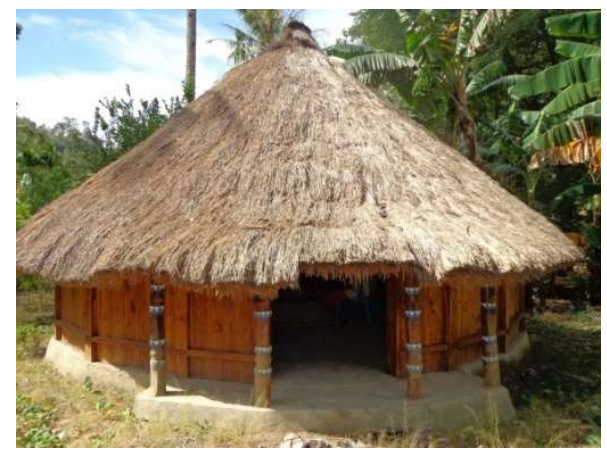

Gambar 3: Ume Kbubu, Januari 2017

Motif tenun bagi masyarakat Nusa Tenggara Timur, khususnya Kabupaten Timor Tengah Utara diyakini mempunyai nilai dan kandungan makna tertentu. Motif tidak hanya membedakan seni budaya dan adat istiadat masing-masing suku, tetapi mempunyai kaitan dengan pralambang status dan kedudukan sosial seseorang dalam 
kehidupan bermasyarakat. Masyarakat yang menggunakan busana bermotif tertentu, orang dapat mengetahui bagaimana latar belakang kehidupan pemakainya, asal usul seseorang yang mengenakan sarung bermotif tersebut serta status sosial.

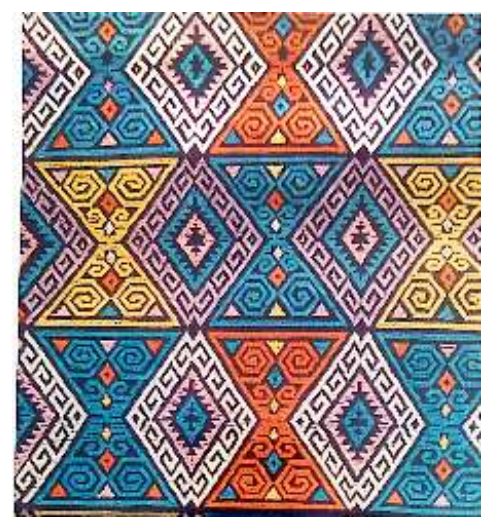

\section{Gambar 4. Tenunan motif buna dalam Lela, 2002) berasal dari daerah Insana}

Menurut Sugihartono (2007: 81), pembelajaran adalah suatu upaya yang dilakukan secara sengaja oleh pendidik untuk menyampaikan ilmu pengetahuan, mengorganisasi, dan menciptakan sistem lingkungan dengan berbagai metode sehingga siswa dapat melakukan kegiatan belajar secara efektif dan efisien serta dengan hasil yang optimal. Dalam UU Nomor 20 Tahun 2003 tentang Sistem Pendidikan Nasional pasal 1 ayat 20 disebutkan bahwa pembelajaran adalah proses interaksi pendidik dengan peserta didik dan sumber belajar pada suatu lingkungan belajar. Erman Suherman (2001: 8) menyatakan pembelajaran merupakan upaya penataan lingkungan yang memberi nuansa agar program belajar tumbuh dan berkembang secara optimal.

Menurut kurikulum 2006, Matematika adalah ilmu universal yang mendasari perkembangan teknologi modern, memiliki peran penting dalam berbagai disiplin ilmu dan mempromosikan kekuatan pikiran manusia.

Menurut Permendiknas Nomor 22 Tahun 2006, pembelajaran matematika di SMP mempunyai beberapa tujuan. Salah satu tujuan pembelajarannya yaitu agar siswa mampu memahami konsep matematika yaitu siswa dapat menjelaskan keterkaitan antarkonsep dan mengaplikasikan konsep atau algoritma, secara luwes, akurat, efisien, dan tepat, dalam pemecahan masalah. Pembelajaran matematika adalah proses interaksi belajar dan mengajar matematika yang melibatkan siswa dan guru, dimana prosesnya dimulai dari hal-hal konkrit ke hal-hal yang abstrak.

\section{METODE}

Metode yang digunakan dalam pelaksanaan pengabdian ini adalah Pelatihan Praktek dalam dua tahap, yaitu tahap pertama Workshop Pembelajaran Matematika 
yang melibatkan guru-guru Matematika tingkat SMP Negeri/Swasta dari empat Kabuputen, yaitu Kabupaten Timor Tengah Selatan (TTS), Timor Tengan Utara (TTU), Belu, dan Malaka yang ikut partisipasi dalam kegiatan Lomba Cerdas Tepat Matematika (LCTM) yang diselenggarakan oleh Himpunan Mahasiswa Program Studi Pendidikan Matematika (HIMPROSMA) tahun 2017 di Kampus Universitas Timor. Pada tahap ini, guru membuat LKS yang sesuai dengan potensi local masyarakat Kefamenanu dengan berpedoman pada kompetensi dasar dan kompetensi inti mata pelajaran matematika. Sedangkan pada tahap kedua, dipilih satu Kabupaten secara acak sebagai tempat Real Teaching, untuk memantau penggunaan hasil pelatihan yaitu LKS berbasis potensi lokal secara mandiri oleh guru mata pelajaran matematika.

\section{HASIL DAN PEMBAHASAN}

Pengabdian ini dilaksanakan dalam dua tahap, yaitu tahap pertama Workshop Pembelajaran Matematika yang melibatkan guru-guru Matematika tingkat SMP Negeri/Swasta dari empat Kabuputen, yaitu Kabupaten Timor Tengah Selatan (TTS), Timor Tengan Utara (TTU), Belu, dan Malaka yang ikut partisipasi dalam kegiatan Lomba Cerdas Tepat Matematika (LCTM) yang diselenggarakan oleh Himpunan Mahasiswa Program Studi Pendidikan Matematika (HIMPROSMA) tahun 2017 di Kampus Universitas Timor. Sedangkan pada tahap kedua, dipilih satu Kabupaten secara acak sebagai tempat Real Teaching, untuk menggambarkan hasil dan merupakan tindak lanjut dari workshop tahap pertama.

\section{Tahap Pembuatan LKS}

Subyek penelitian pada Tahap I adalah Guru-guru Matematika dari empat Kabupaten, yaitu TTS, TTU, Belu, dan Malaka yang dilaksanakan di Student Centre Universitas Timor pada tanggal 22 Mei 2017. Sebelum diberikan pelatihan Pembelajaran Matematika, tim peneliti mempresentasekan materi tentang "Memanfaatkan potensi lokal dalam pembelajaran matematika bagi guru SMP". Hal ini bertujuan agar peserta memiliki pengetahuan secara umum tentang potensi lokal dan pembelajaran matematika beserta kaitannya.

Setelah peserta memahami potensi lokal dan bagaimana memanfaatkannya dalam pembelajaran matematika, tim pengabdi membagi peserta ke dalam empat kelompok, kemudian diberikan Lembar Kerja Guru (LKG). LKG terdiri dari dua aktifitas yaitu, (1) Memilih topik/materi yang cocok dengan konteks Laku Tobe/jambu biji/ ume kbubu/ kain tenun, (2) Kemudian membuat LKS yang sekurang-kurangnya memuat dua soal/pertanyaan sesuai topik/materi yang paling cocok menggunakan konteks Laku Tobe/ jambu biji/ ume kbubu/ kain tenun. Dari hasil kerja kelompok, diperoleh hasil pemilihan topik/materi yang cocok dengan potensi lokal yang diberikan, yaitu, (1) Materi bangun ruang (sisi datar dan sisi lengkung) cocok menggunakan konteks ume 
kbubu dan laku tobe, (2) Materi bangun datar cocok menggunakan konteks kain tenun, (3) Materi bilangan, aritmatika sosial cocok menggunakan konteks jambu biji.

LKS yang dihasilkan guru adalah:

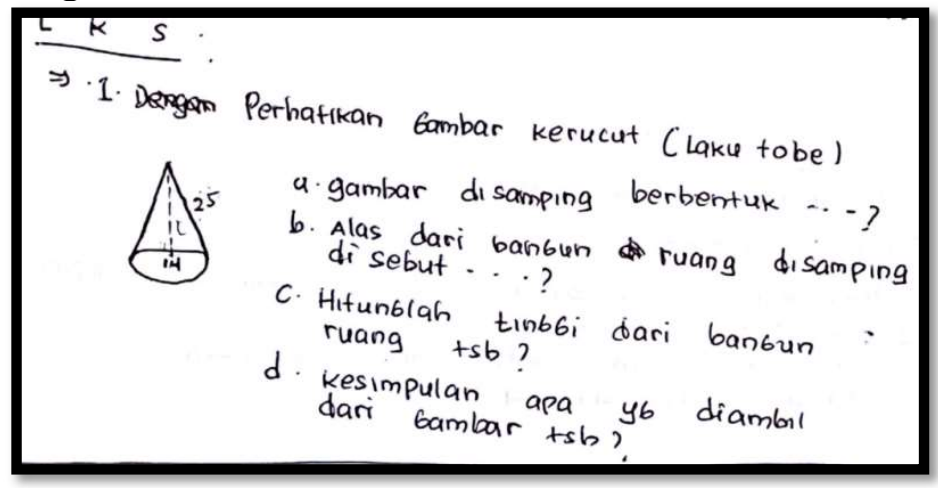

Dari hasil kerja guru yang dibagi dalam kelompok, guru sudah bisa membuat LKS dengan baik menggunakan konteks laku tobe. Pertanyaan yang dibuat oleh guru sudah melebihi target yang diharapkan yaitu minimal dua pertanyaan atau soal dengan konteks laku tobe.

\begin{tabular}{|c|c|}
\hline$\Rightarrow$ KAIN & TENGN (MATORI BANGUN DATAR) \\
\hline & $\begin{array}{l}\text { 1. Berbentuk apakah Bablan-baglan dari Gamban disampin6.... } \\
\text { 2. Jika salah satu bagian dari Gambar } \\
\text { tersebut adalah se6itiba, maka tentukan } \\
\text { rumus luas sebitisa) }\end{array}$ \\
\hline
\end{tabular}

Hasil kerja guru yang dibagi dalam kelompok, untuk konteks kain tenun motif Buna, guru sudah bisa membuat LKS dengan baik menggunakan konteks kain tenun motif Buna. Pertanyaan yang dibuat oleh guru sudah sesuai target yang diharapkan yaitu minimal dua pertanyaan atau soal dengan konteks kain tenun motif Buna. Pertanyaan nomor 1 yang dibuat guru tersebut memuat konsep bentuk-bentuk bangun datar, pertanyaan jenis ini sangat baik untuk mengetahui informasi yang dimiliki siswa. Pertanyaan nomor 2 merupakan lanjutan yang sangat sesuai dengan nomor 1 .

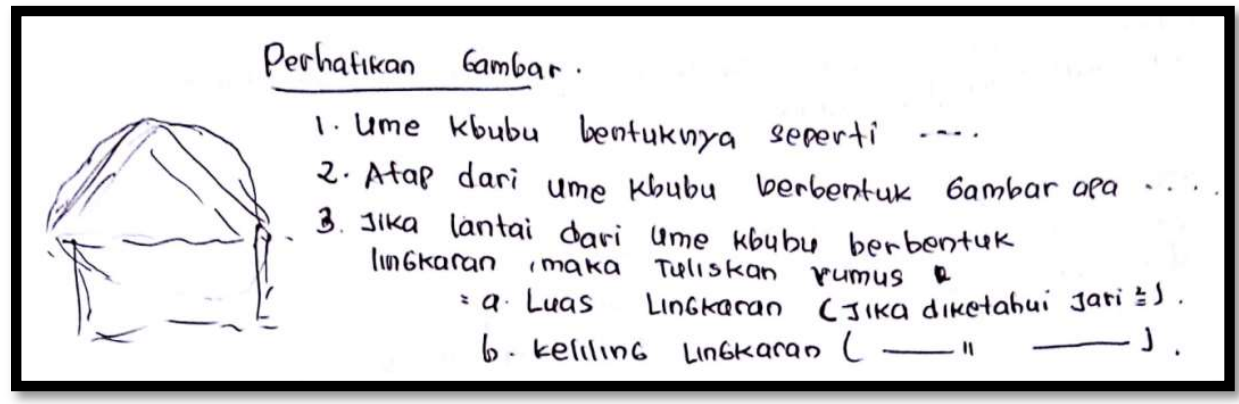

Hasil kerja guru yang dibagi dalam kelompok, untuk konteks ume kbubu, guru sudah bisa membuat LKS dengan baik menggunakan konteks ume kbubu. Pertanyaan yang 
dibuat oleh guru sudah melebihi target yang diharapkan yaitu minimal dua pertanyaan atau soal dengan konteks ume kbubu. Pertanyaan nomor 1 yang dibuat guru sangat baik untuk mengetahui informasi yang dimiliki siswa. Pertanyaan nomor 2 dan 3 menggunakan atap dan lantai ume kbubu untuk menjembatani pengalaman siswa sehari-hari dalam pembelajaran matematika.

Hasil kerja guru pada kelompok 3

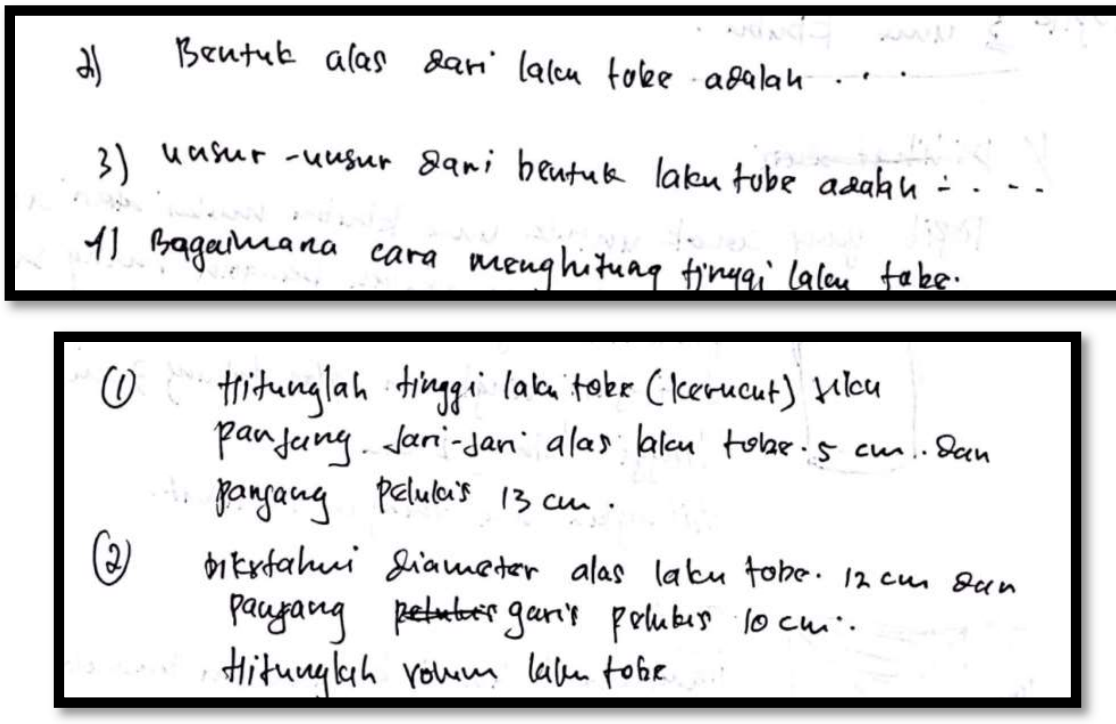

Hasil kerja guru yang dibagi dalam kelompok, guru sudah bisa membuat LKS dengan baik menggunakan konteks laku tobe. Hal ini terlihat dari pertanyaan yang dibuat oleh guru sudah melebihi target yang diharapkan yaitu minimal dua pertanyaan atau soal dengan konteks laku tobe. Pertanyaan yang dibuat oleh guru terlihat bahwa mereka sudah mampu memilih topik yang sesuai dengan potensi lokal laku tobe.

Hasil kerja guru sangat baik, terlihat dari LKS yang dibuat pada saat workshop tahap 1, mereka sangat mengenal potensi lokal yang diberikan karena soal atau pertanyaan yang diberikan sesuai dengan target yang diharapkan. Guru-guru matematika dari empat kabupaten tersebut tidak mengalami kesulitan dalam membuat LKS karena mereka sudah mengajar lebih dari 7 tahun. Pemanfaatan potensi lokal dalam pembelajaran matematika bukanlah hal yang sulit, tetapi yang menjadi kendala selama ini adalah ketidaktahuan bahwa ternyata kehidupan sehari-hari siswa bisa dimanfaatkan sebagai potensi lokal dalam pembelajaran matematika. 


\section{Real Teaching}

Real teaching adalah bagian kedua dari pelatihan pembelajaran Matematika yang dilaksanakan pada tanggal 22 mei 2017. Kegiatan ini dilaksanakan untuk melihat kemampuan guru dalam memanfaatkan potensi lokal yang diberikan dalam melaksanakan pembelajaran di kelas. Hasil observasi di SMPN 1 Kefamenanu, terlihat bahwa peserta workshop pada tahap 1 dalam melaksanakan real teaching dengan menggunakan LKS berbasis potensi lokal.. Observasi kelas pada tanggal 21 Agustus 2017 di kelas VIII SMPN 1 Kefamenanu terlihat bahwa Ibu guru IU telah mampu menggunakan LKS menggunakan konteks motif kain tenun pada materi sifat-sifat segiempat. Demikian juga pak guru MB telah mampu menggunakan konteks jambu biji dalam pembelajaran matematika pada materi pola bilangan. Dampak dari kreativitas guru ini terlihat dari antusias dan semangat siswa mengikuti proses pembelajaran matematika yang memanfaatkan potensi lokal yang ada di sekitar mereka.

\section{SIMPULAN}

Potensi lokal Laku Tobe, Jambu Biji, Ume Kbubu, dan kain tenun yang ada di Kefamenanu telah terbukti meningkatkan kreativitas guru dalam membuat perangkat pembelajaran berupa LKS untuk menjembatani siswa memahami konsep matematika seperti bangun datar, bangun ruang, dan pola bilangan. Untuk itu, disarankan kepada guru untuk mengembangkan bahan ajar menggunakan potensi local yang dekat dekat dengan kehidupan siswanya.

\section{UCAPAN TERIMA KASIH}

Kami menyampaikan terima kasih kepada LPPM universitas Timor yang telah mendanai dan mendukung kegiatan pengabdian ini.

\section{DAFTAR PUSTAKA}

Amsikan, S, Nahak, S. (2017). Hubungan Konsep Ruang Ume Kbubu Desa Kaenbaun Kabupaten Timor Tengah Utara Dengan Konsep Geometri. Prosiding KNPM II UMS

Deda, N., Y, Disnawati, H. (2017). Hubungan Motif Kain Tenun Masyarakat Suku Dawan - Timor Dengan Matematika Sekolah. Prosiding KNPM II UMS

Dima, T.K., Antariksa, Nugroho, A.M. (2013). Konsep Ruang Ume Kbubu Desa Kaenbaun Kabupaten Timor Tengah Utara. Jurnal RUAS, 11(1), 28-3. 
Dominikus, W.S., Toto Nusantara, T., Subanji, \& Muksar, M. (2016). Link Between Ethnomathematics In Marriage Tradition In Adonara Island And School Mathematics. IOSR Journal of Research \& Method in Education (IOSR-JRME), 3(6), 56-62.

La'a, A. S., \& Suwartiningsih, S. (2013). Makna Tenun Ikat bagi Perempuan. KRITIS Jurnal Studi Pembangunan Interdisiplin, 22(1), 21-40.

Lela, L. (2002). Katalog Tenunan Kabupaten Timor Tengah Utara. Dewan Kerajinan Nasional, Daerah Timor Tengah Utara.

Sabilirrosyad. (2016). Ethnomathematics Sasak: Eksplorasi Geometri Tenun Suku Sasak Sukarara dan Implikasinya Untuk Pembelajaran. JURNAL TATSQIF Jurnal Pemikiran dan Penelitian Pendidikan, 4(1), 49-65.

Sugihartono, dkk. (2007). Psikologi pendidikan. Yogyakarta: UNY Press

Suherman, dkk. (2003). Strategi Pembelajaran matematik kontemporer. Bandung : UPI. 